\title{
Bevacizumab purification by peptide affinity chromatography
}

\author{
Gabriela R. Barredo ${ }^{1}$, Silvana L. Giudicessi ${ }^{1}$, Mara C. Martinez-Ceron ${ }^{1}$, Soledad L. Saavedra ${ }^{1}$, Gustavo Mahler ${ }^{2}$, \\ Fernando Albericio $^{3}$, Osvaldo Cascone ${ }^{1}$, Silvia A. Camperi ${ }^{1}$ \\ ${ }^{1}$ Universidad de Buenos Aires. FFyB. At. Biotecnologa. CONICET-UBA, Inst. NANOBIOTEC. Junn 956, 1113, Bs As. , Argentina \\ ${ }^{2}$ AGC Biologics. 22021 20th Avenue SE. Bothell, WA 98021. USA, United States \\ ${ }^{3}$ School of Chemistry, University of KwaZulu-Natal, Durban 4001, South Africa
}

https://doi.org/10.17952/35EPS.2018.130

\section{Introduction}

Therapeutic Monoclonal Antibodies (mAbs) are widely used in the treatment of many diseases. Bevacizumab (trade name: Avastin) inhibits the vascular endothelial growth factor and hence the angiogenesis process. It is used in brain, breast, colorectal, lung and renal cancer treatments (1). Due to its parenteral administration, its degree of purity must be extremely high. Nowadays, that is achieved by affinity chromatography (AC) with immobilized protein A, a highly expensive ligand that increases the cost of the purification process. On the other hand, short peptides are ideal ligands for AC due to their higher stability, easier synthesis and lower cost in comparison to protein A (2). In this work, a short peptide ligand with affinity for Bevacizumab was selected from a peptide library.

\section{Methods}

A one-bead-one-peptide combinatorial library was developed by the divide-couple-recombine method, using the HMBA-ChemMatrix resin as solid support and the Fmoc strategy (3). Bevacizumab (AGC Biologist, USA) was labeled with Texas-Red. After mixing it with the library, fluorescent beads were selected, and the peptides identified by MALDI-TOF MS/MS. Those that appeared most frequently were synthesized in larger quantities on Rink Amide resin and separated from the solid support with TFA cleavage cocktail. Chromatographies were carried out after immobilizing the peptides on PierceTM NHS-activated dry agarose resin. One of the peptides was capable to adsorb IgG from $\mathrm{CHO}$ cell supernatants better than the others, while all the contaminants passed through without interacting with the chromatographic matrix. Adsorption isotherms were performed at room temperature to characterize the generated affinity resin.

\section{Results and Discussion}

Chromatographies with the peptide ligand were performed using pure IgG, $\mathrm{CHO}$ supernatant, and $\mathrm{CHO}$ supernatant spiked with IgG (Fig. 1). 


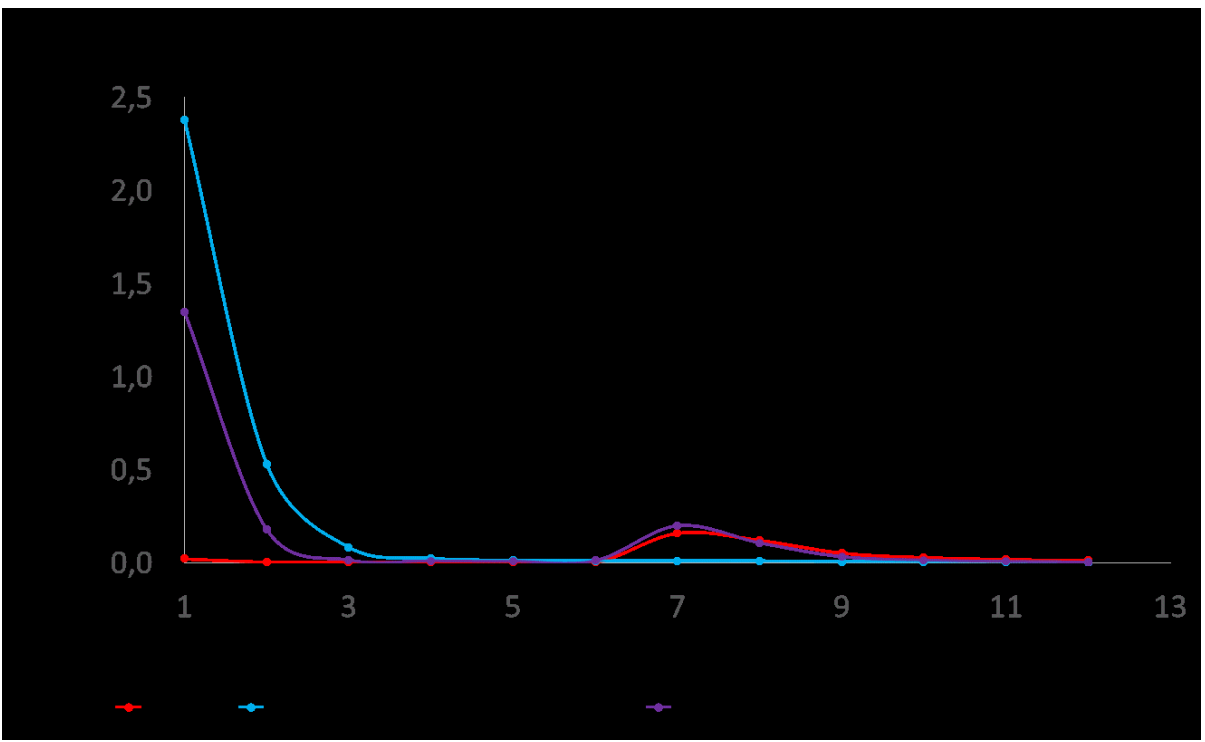

Figure 1: Chromatograms with the peptide ligand. Protein was measured by its absorbance at $280 \mathrm{~nm}$. Pure IgG (red). CHO supernatant (blue). CHO supernatant spiked with IgG (purple).

Chromatographicsamples were loaded on SDS-PAGE (Fig. 2). The peptide AC showed a good selectivity for IgG and no interaction with $\mathrm{CHO}$ supernatantproteins was verified.

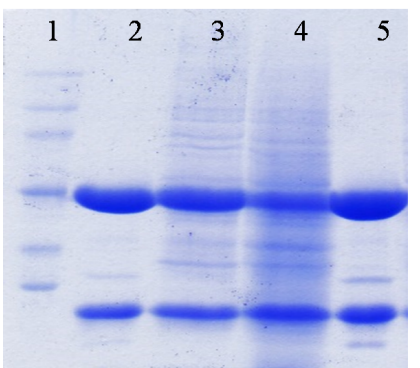

Figure 2: SDS-PAGE of the chromatographic Bevacizumab's purification. Lane 1) Protein molecular weight marker (MW); Lane 2) Standard of pure Bevacizumab; Lane 3) CHO cells supernatant spiked with IgG; Lane 4) and 5) washing and elution fractions of the chromatography respectively.

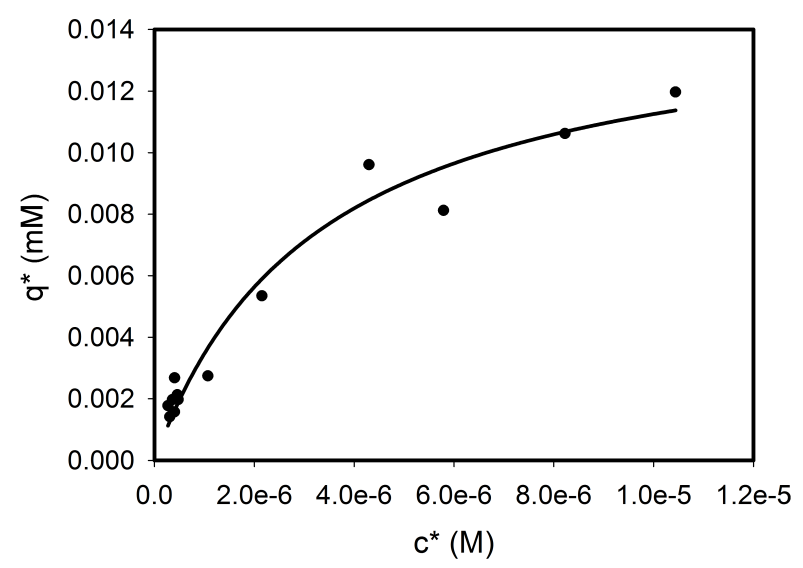

Figure 3: Isotherm carried out at $25^{\circ} \mathrm{C}$ for $2 \mathrm{~h}$.

Fig. 3 shows the adsorption isotherm of Bevacizumab on the peptide support. The isotherm shows a good fit of experimental data to a Langmuir-type isotherm allowing the calculation of a maximum capacity ( $\mathrm{qm}$ ) of 0.015 $\mu$ mol Bevacizumab/mL of matrix and a $\mathrm{Kd}$ of $10^{-6} \mathrm{M}$. 


\section{Conclusions}

One-bead-one-peptide combinatorial libraries seemed to be a useful method to find possible ligand candidates for purifying proteins by affinity chromatography. A peptide was selected according to its frequency of appearance and its performance as an affinity ligand was studied.

The SDS-PAGE of the elution fraction of the AC with the selected peptide showed that only the IgG elutes from the complex mixture. No supernatant protein was detected in the elution fractions while some bands at the same level of IgG bands could be seen in the wash fractions, suggesting that not all IgG could be adsorbed.

The adsorption isotherm showed a $\mathrm{Kd}$ in the range of $10^{-6}$ which is higher than protein $\mathrm{A} \mathrm{Kd}$. However, as no $\mathrm{CHO}$ supernatant protein was found in the elution, this peptide appears to be selective.

\section{Acknowledgements}

S.L.G, M.C.M.C, O.C. and S.A.C. are researchers of the Consejo Nacional de Investigaciones Científicas y Técnicas (CONICET). This work was partially supported by the Universidad de Buenos Aires (20020170100030B A), the Ministerio de Ciencia, Tecnología e Innovación Productiva de la República Argentina (PICT-2014-1508) and the Consejo Nacional de Investigaciones Científicas y Técnicas de la República Argentina (PIP 11220130100119CO).

\section{References}

1. Poku E, Rathbone J, Wong R, Everson-Hock E, Essat M, Pandor A, Wailoo A. BMJ Open. (2014). 17;4(7):e005244. DOI 10.1136/bmjopen-2014-005244

2. Camperi SA, Martínez-Ceron MC, Giudicessi SL, Marani MM, Albericio F, Cascone O. En: Methods Mol Biol. (2014). 1129:277-302. DOI: 10.1007/978-1-62703-977-2_22.

3. Martínez-Ceron MC, Giudicessi SL, Marani MM, Albericio F, Cascone O, Erra-Balsells R, Camperi SA. Anal Biochem. (2010). 400:295-7. doi: 10.1016/j.ab.2010.01.029. 